\section{Dr. Toshiaki Sano}

\section{June 15th 1949-February 10th 2011}

(C) Springer Science+Business Media, LLC 2011

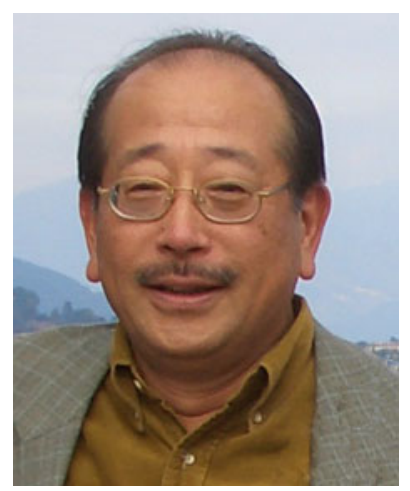

It is with deep regret and sadness that we announce the untimely passing of Dr. Toshiaki Sano on February 10, 2011.

Dr. Sano was an international leader in the field of Endocrine Pathology and a Past President of the Endocrine Pathology Society. He published more than 200 papers on various subjects in that area. His true love was pituitary pathology and he was very active in the Pituitary Pathology Club, having organized its meetings in Hakone, Japan in 1998 and most recently in Awaji, Japan in 2009 when he was President of the organization. Dr. Sano was an extremely meticulous and observant scientist, a mentor to many young pathologists and students, and a warm and dedicated friend to many of his colleagues. As the Chairman and Professor of the Department of Human Pathology, University of Tokushima School of Medicine, he was a major force in ensuring high quality of pathology in Japan.

He will be sorely missed by his wife, Nobuko, his daughter Rena, his son Toshinori, and his many friends and colleagues throughout the world.

Sylvia L. Asa and Kalman Kovacs. 